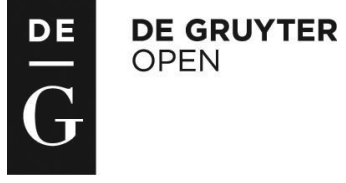

\title{
INDUCTION OF THE SECRETION OF LH AND GH BY OREXIN A AND GHRELIN IS CONTROLLED IN VIVO BY LEPTIN AND PHOTOPERIOD IN SHEEP*
}

\author{
Katarzyna Kirsz ${ }^{1}$, Małgorzata Szczęsna ${ }^{1}$, Edyta Molik ${ }^{1}$, Tomasz Misztal ${ }^{2}$, Dorota A. Zięba ${ }^{1 \bullet}$ \\ 'Department of Animal Biotechnology, Laboratory of Biotechnology and Genomics, \\ Agricultural University of Krakow, Rędzina 1B, 31-248 Kraków, Poland \\ ${ }^{2}$ Department of Endocrinology, The Kielanowski Institute of Animal Physiology and Nutrition, \\ Polish Academy of Sciences, Instytucka 3, 05-110 Jabłonna, Poland \\ •Corresponding author: rzzieba@cyf-kr.edu.pl
}

\begin{abstract}
The influence of leptin on orexin $A$ and the interaction of leptin with ghrelin in regulating the gonadotropic and somatotropic axes in seasonally polyestrous animals are not well understood. This study examined the effects of these factors as well as the mediating roles of specific ovine leptin antagonist (SOLA; mutant D23L/L39A/D40A/F41A) and photoperiod on luteinizing hormone (LH) and growth hormone (GH) secretion. Twenty-four ovariectomized, estradiol-implanted ewes were used in a replicated switchback design. The ewes were assigned randomly to 1 of 6 treatments (infused into the third ventricle 3 times at 0 (dusk), 1, and 2 h) as follows: control, Ringer-Locke buffer; leptin, $0.5 \mu \mathrm{g} / \mathrm{kg}$ b.w.; orexin A, $0.3 \mu \mathrm{g} / \mathrm{kg}$ b.w.; ghrelin, $2.5 \mu \mathrm{g} / \mathrm{kg}$ b.w.; SOLA, $50 \mu \mathrm{g} / \mathrm{kg} \mathrm{b.w.}$ $+\operatorname{orexin~A,~} 0.3 \mu \mathrm{g} / \mathrm{kg}$ b.w.; and SOLA, $50 \mu \mathrm{g} / \mathrm{kg} \mathrm{b.w.} \mathrm{+} \mathrm{ghrelin,} 2.5 \mu \mathrm{g} / \mathrm{kg}$ b.w. Blood samples (5 ml) were collected at 15-min intervals for $4 \mathrm{~h}$. SOLA + orexin A resulted in an increase $(P<0.01)$ in the LH plasma concentration during short-day (SD) and long-day (LD) photoperiods. However, ghrelin and SOLA + ghrelin had the opposite effect. SOLA + orexin A resulted in an increase $(\mathrm{P}<0.001)$ in the GH concentration compared with leptin or orexin A during the LD season. Ghrelin and SOLA + ghrelin increased the GH concentration $(\mathrm{P}<0.01)$ regardless of the season. In summary, LH and GH secretion are seasonally dependent on relationships that are subject to photoperiodic regulation, and leptin is an important regulator of the effects of ghrelin and orexin A on the activities of the gonadotropic and somatotropic axes in sheep.
\end{abstract}

Key words: leptin antagonist, orexigenic hormones, luteinizing hormone, growth hormone, sheep

Leptin is an important peripheral factor that participates in the mechanism linking energy status with the activity of hormones that regulate reproduction and growth

*Source of research financing: This work was supported by the Polish National Science Center (grant NCN 2012/05/B/NZ4/02408). 
processes (Amstalden et al., 2003; Zieba et al., 2003 a, b). The identification of the leptin receptor in the central nervous system (CNS) has enabled the elucidation of the functional and anatomical relationships of leptin activity with the pathways of neuropeptides and hormones involved in energy balance control and the gonadotropin and somatotropin axes, including orexin A and ghrelin (Anukulkitch et al., 2010; Kirsz et al., 2012; Sirotkin and Grossmann, 2007).

In rodents, intracerebroventricular (ICV) leptin injections significantly decrease orexin A immunoreactivity in neurons (Sun et al., 2006) and the expression of its precursor, prepro-orexin (pORX), in the hypothalamus (Tritos et al., 2001). Anukulkitch et al. (2010) demonstrated that the levels of pORX gene expression in the lateral hypothalamus, perifornical nucleus (pfA) and dorsomedial nucleus (DMH) are negatively correlated with the amount of accumulated body fat and the leptin concentration in the blood plasma of genetically selected lean and obese sheep. Ghrelin is not secreted exclusively by cells of the gastrointestinal tract. Reductions in ghrelin secretion and mRNA expression have been observed in the hypothalamus and pituitary gland of obese mice carrying a mutation in the leptin gene (ob) (Luque et al., 2007). However, Kirsz et al. (2012) observed that exogenous leptin and specific ovine leptin antagonist influence the concentrations of peripheral orexin and ghrelin, which are dependent on the photoperiod, and leptin and its antagonists influence the secretory activities of the pituitary (Kirsz et al., 2014) and pineal glands of sheep (Zieba et al., 2011).

The roles of energy metabolism indicators in the regulation of reproduction and growth are relatively well understood (Clarke, 2014), but studies of the multitude of factors (e.g., nutritional status, the sex, age and species of animals and photoperiod) that interfere with the relationship between these indicators and pituitary tropic hormones have often reported conflicting data. The influences of orexin A and ghrelin on the secretion of luteinizing hormone ( $\mathrm{LH})$ and growth hormone $(\mathrm{GH})$ are distinct and depend on the animal model (Barb and Matteri, 2005; Chen and Xu, 2003; Small et al., 2003).

Sheep are short-day breeders that provide a very interesting model for studying interactions between the environment and endocrine status. These interactions enable sheep to survive periods of reduced food availability and impact their reproductive and growth cycle processes (Zieba et al., 2008 b). Sheep, in contrast to other livestock species, exhibit natural seasonal leptin resistance (Zieba et al., 2008 a); this resistance is related to the adaptation of ruminants to yearly changes in energy demand (Zieba et al., 2008 b).

Leptin may alter the relationship between orexin A and ghrelin and the activities of the gonadotropic and somatotropic axes. This study analyzed the relationship between leptin and orexin A and ghrelin in relation to $\mathrm{LH}$ and $\mathrm{GH}$ secretion using a leptin antagonist (SOLA). The influence of these hormones was examined by performing ICV infusions in the lumen of the third ventricle of sheep brains. The research was performed during autumn-winter (SD; short days) and spring-summer (LD; long days) periods to determine the possible impact of the season on hormone concentrations. 


\section{Material and methods}

\section{Animals}

The Local Agricultural Animal Care and Use Committee in Kraków, Poland, approved all procedures performed on the animals in this study. The experiments were conducted at the Experimental Station of the Department of Animal Biotechnology, Agricultural University of Krakow, Poland (longitude, 1957'E; latitude, $\left.50^{\circ} 04^{\prime} \mathrm{N}\right)$.

The present study utilized 24 Polish Longwool ewes that exhibit pronounced reproductive seasonality. The breeding season commences during shortening days (August-December), and a period of seasonal anestrus (non-breeding season) ensues as days become longer (February-June). The animals were 3 years of age, weighed $65 \pm 4 \mathrm{~kg}$ and were housed in individual pens under natural photoperiodic and thermoperiodic conditions. All sheep presented good body condition scores $[\mathrm{BCS}=3$ on a scale of 1 to 5 (Russel et al., 1969)]. The present experiments were performed during the LD photoperiod from April to May, when the average day length in Poland is approximately $15 \mathrm{~h}$, and the SD photoperiod in October and November, when the day length averages $9 \mathrm{~h}$. The ewes were ovariectomized approximately 2 months before the experiments and implanted with estradiol-releasing subcutaneous implants as previously described in our studies of the effects of anorectic and orexigenic peptides in sheep (Kirsz et al., 2012). The mean circulating concentration of estradiol throughout the entire study period was $3.9 \pm 0.3 \mathrm{pg} / \mathrm{ml}$. This ovine experimental model is a widely accepted neuroendocrine model that was developed to avoid the confounding effects of the ovarian cycle on hormonal interactions and to provide constant physiological concentrations of estrogens and steroid-mediated feedback on the secretory activities of the hypothalamus and adenohypophysis (Amstalden et al., 2002; Zieba et al., 2008 a).

The sheep were fitted surgically with intracerebroventricular cannulae one month before the beginning of the study according to the methodology of Traczyk and Przekop (1963). Continuous flow of cerebrospinal fluid verified the location and function of the cannulae. A period of at least 3 weeks was allowed for recovery from neurosurgery.

\section{Experimental procedures and treatments applied}

The ewes were randomly allocated to one of six equinumerous groups $(n=4 /$ group) during both seasons. The sheep received a formulated diet twice daily $(0700 \mathrm{~h}$ and $1400 \mathrm{~h}$ ) to provide $100 \%$ of the National Research Institute of Animal Production's recommendations for maintenance (Norms, 1993). Water and mineralized salt licks were available to the animals ad libitum. In the morning on the day of experiment, sheep were fitted with jugular catheters for intensive blood sampling. Subsequently, females from each group were restrained into individual sampling carts to familiarize them with the experimental conditions. Carts were constructed of wood with solid floors, and allowed animals to stand or lie down freely during sampling procedures. Finally, polyethylene tubing $(0.58-\mathrm{mm}$ i.d., 0.96-mm o.d.; Intramedic Caly Adams Brand, Becton Dickinson, Sparks, MD, USA) was inserted using 
an aseptic technique through each ICV-guided cannula according to Zieba et al. (2008 a) and Kirsz et al. (2012) and the flow of cerebrospinal fluid was confirmed.

The ewes were allocated to the following treatment groups: Group 1 (control), Ringer-Locke buffer, $\mathrm{pH} 7.4$; Group 2, recombinant ovine leptin (LEPT; $0.5 \mu \mathrm{g} / \mathrm{kg}$ b.w.) (PLR Laboratory, Rehevot, Israel); Group 3, rat orexin-A (ORXA; $0.3 \mu \mathrm{g} / \mathrm{kg}$ b.w.) (PolyPeptide Laboratories, Strasbourg, France); Group 4, ovine ghrelin (GHRL; $2.5 \mu \mathrm{g} / \mathrm{kg}$ b.w.) (PolyPeptide Laboratories, Strasbourg, France); Group 5, ovine pegylated leptin antagonist (SOLA, mutant D23L/L39A/D40A/F41A; $50 \mu \mathrm{g} /$ kg b.w.) (PLR Laboratory, Rehevot, Israel) + ORXA at the same dose as above; and Group 6, SOLA + GHRL at the same doses as above. Ringer-Locke buffer, LEPT, ORXA and GHRL were ICV infused at 0,1 and $2 \mathrm{~h}$ during the 4-h experiment (in 3 single infusions of $100 \mu \mathrm{l}$ each) (Figure 1). SOLA was infused centrally in Groups 5 and 6 twice, at 0 and $1 \mathrm{~h}$ of the experiment, and ORXA or GHRL was infused at 15 and $60 \mathrm{~min}$ after the second infusion of SOLA (Figure 1). The treatments for each group were replicated twice in four randomly chosen ewes approximately 1 week apart ( $n=8$ treatment). The appropriate dose of leptin for the ICV study was determined in our previous experiments (Kirsz et al., 2012; Zieba et al., 2008 a), and the doses of ORXA, GHRL, and SOLA were based on both theoretical calculations and published studies involving ICV injections in sheep (Harrison et al., 2008; Kirsz et al., 2012; Sartin et al., 2001).

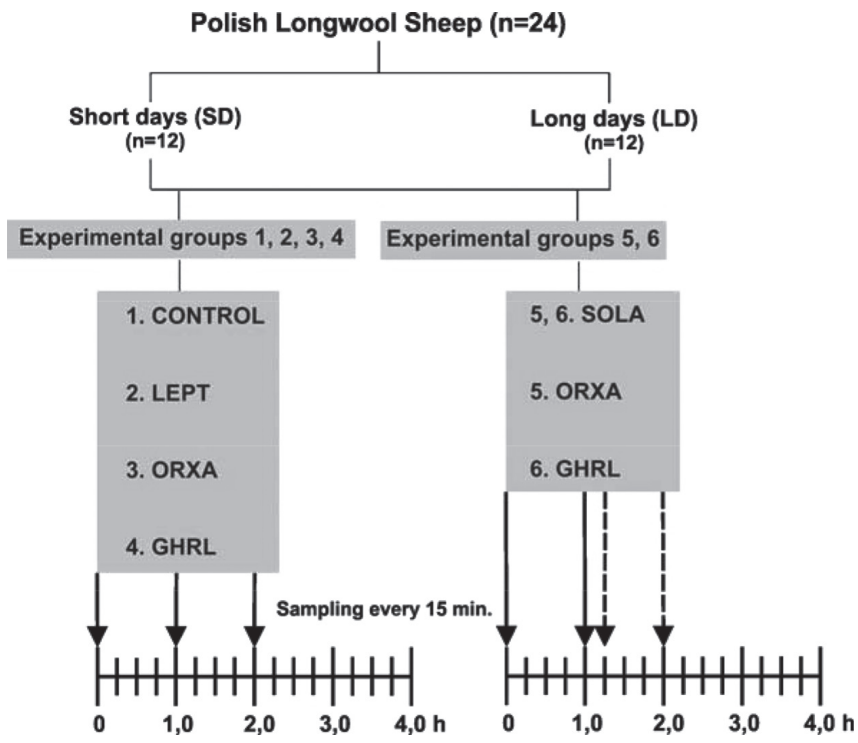

Figure 1. Experimental design and treatments applied. Sheep were maintained under short days (SD; $9 \mathrm{~h}$ light:15 h darkness) for two months (October-November), followed by two months (April-May) of long days (LD; $15 \mathrm{~h}$ light:9 h darkness). The treatments were as follows: 1) Ringer-Locke buffer (control); 2) leptin (LEPT; $0.5 \mu \mathrm{g} / \mathrm{kg}$ b.w.); 3) orexin A (ORXA; $0.3 \mathrm{mg} / \mathrm{kg}$ b.w.); 4) ghrelin (GHRL; $2.5 \mu \mathrm{g} / \mathrm{kg}$ b.w.); 5) leptin antagonist (SOLA) and ORXA; and 6) SOLA and GHRL. The arrows indicate intracerebroventricular (ICV) injections given at $0,1,1.15$ and $2 \mathrm{~h}$ during the 4-h experimental period. Blood samples $(5 \mathrm{ml})$ were collected at 15 -min intervals throughout the experiment 
Blood sample $(5 \mathrm{ml})$ collection began at dusk and was performed at 15 -min intervals for $4 \mathrm{~h}$, beginning prior to the first infusion (Figure 1). The blood samples were dispensed into tubes containing $150 \mu \mathrm{l}$ of a solution of heparin $(10,000 \mathrm{IU} / \mathrm{ml})$ and 5\% (wt/vol) EDTA and immediately placed on ice. Plasma was separated by centrifugation at $3,000 \times \mathrm{g}$ for $10 \mathrm{~min}$ at $4^{\circ} \mathrm{C}$ and stored at $-20^{\circ} \mathrm{C}$ until analyses of estradiol, $\mathrm{LH}$, and $\mathrm{GH}$.

\section{Hormone assays}

Estradiol concentrations were determined using commercially available EIA kits (DRG Instruments GmbH, Marburg, Germany) according to the manufacturer's instructions. All samples were analyzed in duplicate in the same assay. The inter- and intra-assay precision values exhibited a coefficient of variation (CVs) of $4.55 \%$. Assay sensitivity was $1.7 \mathrm{pg} / \mathrm{ml}$.

LH concentrations were measured using a double antibody (anti-ovine LH and anti-rabbit $\gamma$-globulin antisera) radioimmunoassay developed by Stupnicki and Madej (1976) and a bovine LH standard (NIH-LH-B6). The assay sensitivity was $0.3 \mathrm{ng} / \mathrm{ml}$, and the inter- and intra-assay coefficients of variation were $6.7 \%$ and $11.2 \%$, respectively. Plasma GH concentrations were also determined using a validated radioimmunoassay with anti-bovine $\mathrm{GH}$ anti-rabbit $\gamma$-globulin antisera and a bovine GH standard (NIDDK-GH-B-1003A) as previously described by Dvorak et al. (1978). The assay sensitivity was $0.6 \mathrm{ng} / \mathrm{ml}$, and the inter- and intra-assay coefficients of variation were $5.9 \%$ and $10.2 \%$, respectively.

\section{Statistical analysis}

The data were subjected to Grubbs' test (the maximum normed residual test) to identify outliers and analyzed using a series of two-way ANOVAs with SigmaPlot ${ }^{\circledR}$ statistical software (version 11.0; Systat Software Inc., Richmond, CA, USA). The collection time values were averaged to calculate means, which were used for comparisons between treatment groups. The statistical models included the main effects of the reagent treatment and season (SD compared with LD). All data sets that failed normality and/or equal variance tests were transformed by the natural logarithm. If the main effects or their interactions were significant, the Holm-Sidak test was used as a post hoc test to compare the individual means. $\mathrm{P}<0.05$ was considered statistically significant. The results are presented as the mean \pm standard error (SE).

\section{Results}

\section{Estradiol concentration}

The mean circulating concentration of estradiol was $3.54 \pm 0.2 \mathrm{pg} / \mathrm{ml}$.

\section{LH concentration}

The average plasma LH concentrations were significantly higher $(\mathrm{P}<0.01)$ in sheep that received Ringer-Locke buffer, LEPT, ORXA, or SOLA + ORXA during the SD period than those observed during the LD period (Figure 2). 
ICV infusions of ORXA during the SD period did not significantly alter the average plasma LH concentration compared with treatments with Ringer-Locke buffer or LEPT. However, SOLA + ORXA administration significantly increased $(\mathrm{P}<0.01) \mathrm{LH}$ secretion in all evaluated groups during both photoperiods (Figure 2).

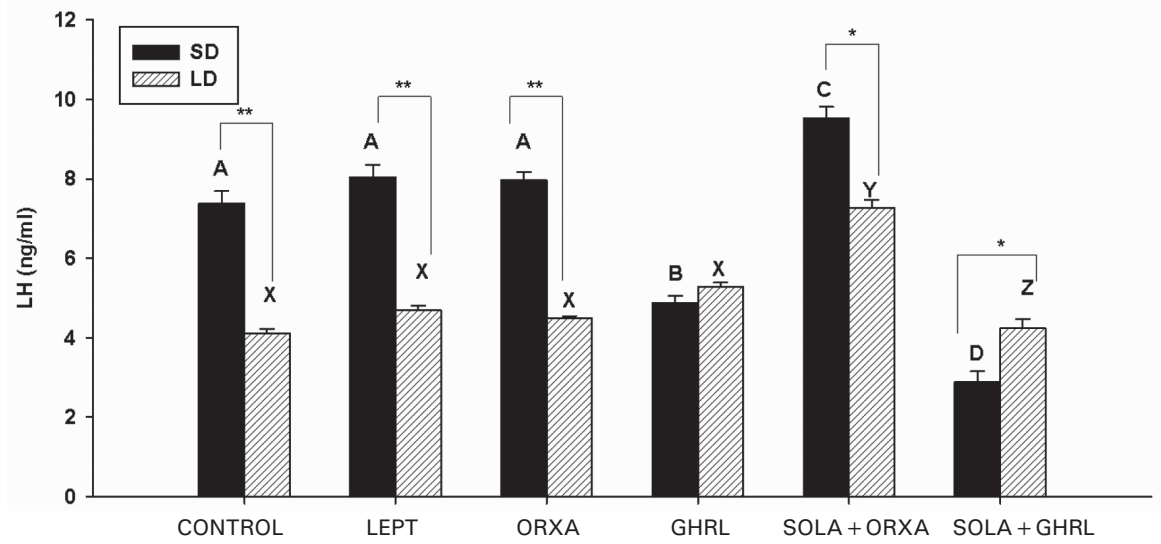

Figure 2. Mean $( \pm \mathrm{SE})$ circulating concentrations of luteinizing hormone $(\mathrm{LH})$ in normally fed Polish Longwool ewes during the short- (SD) and long-day (LD) seasons when subjected to the following treatments: 1) Ringer-Locke buffer (Control); 2) leptin (LEPT; $0.5 \mu \mathrm{g} / \mathrm{kg}$ b.w.); 3) orexin A (ORXA; $0.3 \mathrm{mg} / \mathrm{kg}$ b.w.); 4) ghrelin (GHRL; $2.5 \mu \mathrm{g} / \mathrm{kg}$ b.w.); 5) leptin antagonist (SOLA; $50 \mu \mathrm{g} / \mathrm{kg}$ b.w.) with ORXA; or 6) SOLA with GHRL. The values denoted by asterisks or different letters are significantly different: * indicates $(\mathrm{P}<0.05)$; ** indicates $(\mathrm{P}<0.01)$; ABCXYZ denote $(\mathrm{P}<0.01)$; and $\mathrm{D}$ denotes $(\mathrm{P}<0.001)$

The influence of GHRL on LH concentration depended on the season. Ghrelin inhibited $(\mathrm{P}<0.01) \mathrm{LH}$ secretion during the SD season, but no influence of GHRL on the endogenous LH concentration compared to the control and LEPT-treated groups was observed during the LD season. However, SOLA + GHRL infusion strengthened $(\mathrm{P}<0.001)$ the inhibitory effect of GHRL on LH secretion during the SD season and decreased $(\mathrm{P}<0.01)$ the plasma concentrations of $\mathrm{LH}$ in all studied groups during the LD season. The increase $(\mathrm{P}<0.05)$ in the LH concentration during the LD season compared with the SD season was confirmed within each group (Figure 2).

\section{GH concentration}

Seasonal variations in the concentrations of GH were observed. In the control group, treatments with ORXA and SOLA + ORXA increased GH concentrations during LD season compared to $\mathrm{SD}$ photoperiod ( $\mathrm{P}<0.05$ and $\mathrm{P}<0.01$, respectively).

Increase $(\mathrm{P}<0.01)$ in the endogenous $\mathrm{GH}$ concentration was observed in the LEPT group during the SD season compared with LD season (Figure 3). 


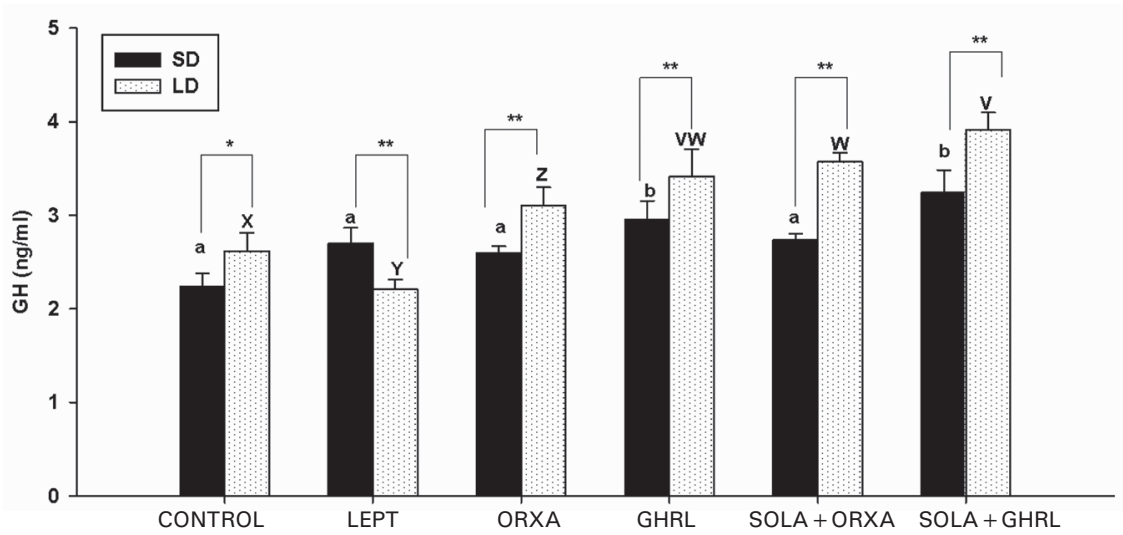

Figure 3. Mean $( \pm \mathrm{SE})$ circulating concentrations of growth hormone $(\mathrm{GH})$ in normally fed Polish Longwool ewes during the short- (SD) and long-day (LD) seasons when subjected to the following treatments: 1) Ringer-Locke buffer (Control); 2) leptin (LEPT; $0.5 \mu \mathrm{g} / \mathrm{kg}$ b.w.); 3) orexin A (ORXA; $0.3 \mathrm{mg} / \mathrm{kg}$ b.w.); 4) ghrelin (GHRL; $2.5 \mu \mathrm{g} / \mathrm{kg}$ b.w.); 5) leptin antagonist (SOLA; $50 \mu \mathrm{g} / \mathrm{kg}$ b.w.) with ORXA; or 6) SOLA with GHRL. The values denoted by asterisks or different letters are significantly different: * indicates $(\mathrm{P}<0.05)$; ** indicates $(\mathrm{P}<0.001)$; ab indicate $(\mathrm{P}<0.05)$; XYZ denote $(\mathrm{P}<0.01)$; and WV denote $(\mathrm{P}<0.001)$

Treatments with ORXA increased $(\mathrm{P}<0.01) \mathrm{GH}$ concentration in LD season compared with controls and leptin-treated sheep (Figure 3). SOLA + ORXA strengthened $(\mathrm{P}<0.001)$ the stimulating effect of ORXA on GH secretion compared with all treatment groups. A combination of SOLA and ORXA as well as LEPT and ORXA alone did not cause significant changes in the concentrations of the GH during SD season (Figure 3).

ICV infusions of GHRL increased GH concentration during the SD season $(\mathrm{P}<0.05)$ and the LD season $(\mathrm{P}<0.01)$ compared with controls, LEPT and GHRL. Treatments with SOLA + GHRL during the SD and LD seasons produced similar effects on the average GH concentration in the blood plasma as GHRL alone. These results confirmed that the GH concentration in GHRL or SOLA + GHRL was lower $(\mathrm{P}<0.01)$ when the infusions were conducted during the SD season compared with the LD season (Figure 3).

\section{Discussion}

The average LH concentration was significantly higher in Control group during the autumn-winter (SD) period compared with LH concentration noted in sheep during experiments conducted during the spring-summer (LD) period (Zieba et al., 2003 b, 2008 b). Central infusion of leptin did not affect LH secretion during either season. This result is consistent with previous studies of ruminants fed ad libitum 
(Amstalden et al., 2002; Miller et al., 2002), which have demonstrated that only nutritional stress triggered by food restriction (from $78 \mathrm{~h}$ to 71 days) increases the sensitivity of the hypothalamic-pituitary axis to exogenous leptin (Polkowska et al., 2012; Towhidi et al., 2007; Wójcik-Gładysz et al., 2009). Subcutaneous administration of leptin in wethers with estradiol implants increases LH concentrations reduced by 78 -h dietary restrictions (Nagatani et al., 2000). In the same animal model, Miller et al. (2002) observed that ICV infusion of leptin in wethers fed ad libitum changed the profile of LH secretion, but the average plasma LH concentrations did not differ significantly between groups.

The weakening of leptin activity due to treatment with its antagonist (SOLA) strengthened the individual effects of orexin A and ghrelin on LH secretion in this study. Intracerebroventricular infusions of orexin A alone did not significantly affect the blood plasma LH concentration in sheep, but the administration of orexin A together with SOLA resulted in the stimulation of LH secretion by orexin A during both periods compared with all other treatment groups. These results suggest an antagonistic role of leptin in the regulation of $\mathrm{LH}$ release by orexin A, which is further increased during the SD period, when increased sexual activity occurs in sheep.

Archer et al. (2002) first noted the potential involvement of orexin in sheep breeding based on annual changes in pORX gene expression in the hypothalamus. Other studies in rodents have suggested that orexin A plays an important role in the regulation of $\mathrm{LH}$ secretion depending on the presence of steroid hormones. Orexin A inhibits LH secretion in ovariectomized animals (Tamura et al., 1999) but stimulates LH secretion in ovariectomized animals with estradiol implants (Kohsaka et al., 2001; Pu et al., 1998).

There are no reports on the interaction between orexin A and leptin in LH secretion, but the identification of the leptin receptor gene in orexin-positive neurons may represent anatomical evidence supporting the relationship between orexin A and leptin (Iqbal et al., 2001). This interaction applies mainly to the pfA, DMH and zona incerta, where $30 \%$ of orexin neurons reach the preoptic area (POA), the primary site of the direct impact of orexin A on gonadotropin-releasing hormone $(\mathrm{GnRH})$ release in sheep (Iqbal et al., 2001). Orexin neurons likely act as intermediaries in the transmission of information carried by leptin to the pulse generator, GnRH. Melanocortin and kisspeptin (Backholer et al., 2009) are hypothalamic factors in sheep that use orexin to transmit their signals, whereas NPY is used in rodents (Russell et al., 2001).

In the present study, the influence of ICV ghrelin infusions on LH secretion was dependent on the photoperiod and SOLA administration. Exogenous ghrelin significantly reduced the blood plasma LH concentration in the sheep; however, this effect was observed only during the SD season. Iqbal et al. (2006) obtained similar results following ICV infusions of DAP-octanol ghrelin in ewes during seasons of reproductive activity. Harrison et al. (2008) confirmed that significant reductions in the frequency and amplitude of LH pulses are influenced by centrally administered ghrelin during SD photoperiods. However, Harrison et al. (2008) observed differences in the average LH concentration between the groups of examined sheep. In another 
study, simultaneous ghrelin injections together with an analog of GnRH decreased the GnRH-induced secretion of LH in a model of superovulated ewes (Dovolou et al., 2013).

Our results confirmed that the weakening of endogenous leptin function following the application of a leptin antagonist strengthened the inhibitory effect of ghrelin on LH secretion. Central infusions of SOLA with ghrelin significantly decreased blood plasma LH concentrations in the sheep compared with all other treatment groups during both seasons. The available data only indicate the individual roles of leptin and ghrelin in the regulation of tropic hormone secretion. However, these data suggest that ghrelin and leptin interact antagonistically in virtually every aspect of the development and functioning of animal reproductive systems, including the process of achieving sexual maturity (Sirotkin et al., 2008), steroidogenesis (Sirotkin and Grossmann, 2007; Spicer and Francisco, 1997; Zachow and Magoffin, 1997), and the functioning of GnRH pulse generators (Lebrethon et al., 2007).

The present study is the first to demonstrate that the application of an antagonist of leptin causes hormones with the same metabolic properties, i.e., orexin A and ghrelin, to exert opposing effects on LH secretion. The dominant view is that the application of compounds with orexigenic properties, particularly in a negative energy balance situation, reduces LH secretion because the information flowing to the CNS via these hormones indicates that the body energy is unbalanced. Therefore, the accumulated energy reserves are primarily used to maintain basic bodily functions (e.g., breathing and thermoregulation), and the need to preserve the species becomes a lesser priority (Clarke, 2014). However, our results suggest that orexin A is not a part of this scheme, and its biological function has not been fully recognized.

Annual differences in GH secretion were observed, including a marked increase during the LD vs. SD photoperiod. This pattern of GH secretion in animals exhibiting metabolic processes characterized by strongly marked seasonality is associated with the anabolic activity of this hormone. Growth during the spring-summer period allows animals to collect the energy reserves that they use during the autumn-winter period, when there is a limited possibility of obtaining food in the environment (Barenton et al., 1988; Harrison et al., 2008).

The effect of leptin activity was only observed during the LD season, when it caused a significant decrease in the endogenous GH concentration. These results are in agreement with those of Szczesna et al. (2013), who reported that GH secretion increases proportionally with the applied leptin dose $(0.5 \mu \mathrm{g} / \mathrm{kg} \mathrm{b}$.w. and $1.0 \mu \mathrm{g} /$ $\mathrm{kg}$ b.w.) during the SD period and decreases during the LD period in sheep. Leptin administration to the lateral ventricles of the brain has been shown to cause a $41 \%$ decrease in somatostatin (SRIF) expression and a $62 \%$ increase in somatoliberin $(\mathrm{GHRH})$ expression in rats fed ad libitum, which is associated with the stimulation of GH mRNA expression in the pituitary (Cocchi et al., 1999). The influence of leptin on GH secretion has also been observed in in vitro studies of bovine (Accorsi et al., 2007; Nonaka et al., 2005; Zieba et al., 2003 a) and ovine somatotrophs (Kirsz et al., 2014). However, the effect of leptin activity depends on several factors, such as the animal species, energy status, and the dose and duration of the activities of exogenous hormones. 
The pattern of yearly GH release after ICV orexin A infusion is opposite that shaped by leptin. However, the use of SOLA together with orexin A increased plasma $\mathrm{GH}$ concentrations in the ewes during the LD photoperiod, in contrast to the groups treated with only leptin or orexin A. Few reports have suggested a relationship between orexin A and somatotropic axis activity. López et al. (2004) and Seoane et al. (2004) confirmed the inhibitory effect of orexin A on GH secretion in the blood of rats fed ad libitum. In another study, orexin B administration to the lateral ventricle or intravenous administration did not influence changes in the GH plasma concentration in wethers (Sartin et al., 2001).

Mechanisms for $\mathrm{GH}$ similar to those underlying the regulation of $\mathrm{LH}$ secretion by SOLA together with orexin A can be suggested. Leptin may transmit its signal via orexin A neurons to the periventricular nucleus of the hypothalamus $(\mathrm{PeN})$, which is the principal area of activity for SRIF and an important area of orexin A influence on GH secretion. Notably, the number of connections between SRIF neurons and orexin neurons in the PeN depends on the amount of accumulated adipose tissue. Significant decreases in the number of connections have been observed in lean sheep, and increased connections have been observed in obese individuals (Iqbal et al., 2005). The weakening of leptin activity induced by SOLA in our study, together with the influence of photoperiod, could have signaled the reduced amount of collected energy reserves to the PeN, causing an increase in the secretion of GH that was further stimulated by the action of exogenous orexin A, thereby reducing the activity of SRIF.

Ghrelin was a much more powerful stimulant of GH secretion than orexin A in our study. ICV infusion of ghrelin significantly increased plasma GH levels in the sheep regardless of day length. Similar changes in the secretion of endogenous GH under the influence of ghrelin in ovariectomized ewes (Grouselle et al., 2008; Iqbal et al., 2006), goats and heifers (Hashizume et al., 2005) have been reported. However, Harrison et al. (2008) observed no differences in average GH concentrations after a single ghrelin infusion to the ovine third ventricle under the influence of exogenous hormone treatment and changes in day length.

Previous experiments in goats, cows (Hashizume et al., 2005) and sheep (Iqbal et al., 2006) and our own studies have demonstrated that ghrelin significantly affects the endogenous $\mathrm{GH}$ concentration, even at relatively low doses (from $0.25 \mu \mathrm{g} / \mathrm{kg}$ b.w. to $20 \mu \mathrm{g} / \mathrm{kg}$ b.w.). The effect of ghrelin on food intake is noticeable in sheep only at concentrations exceeding $100 \mu \mathrm{g} / \mathrm{kg}$ b.w. (Grouselle et al., 2008; Iqbal et al., 2006). This observation suggests that ghrelin acts more effectively as a stimulator of $\mathrm{GH}$ secretion than as an initiator of food intake in ruminants. Our research suggests that the role of ghrelin in GH release is sufficiently strong to overshadow the effect of photoperiod.

Central infusions of SOLA together with ghrelin increased plasma GH concentrations only slightly compared with the group of ewes treated with ghrelin alone but considerably increased GH compared with the other groups. These changes were similar during the SD and LD photoperiods. These results suggest that leptin in the hypothalamus does not play a key role in the regulation of GH secretion by ghrelin, which has previously been demonstrated at the pituitary gland level in sheep (Kirsz 
et al., 2014). The potential impact of leptin may be too weak to eclipse or escalate the effect of ghrelin.

\section{Conclusion}

Based on results of present experiments, the conclusion arises that leptin, a hormone that informs CNS of the energy supplies in adipose tissue, can affect reproduction and metabolism in multiple ways. This is manifested through the effects of leptin on orexin A and ghrelin influence on the activity of gonadotropic and somatotropic axes. Our study reveals a strict network of mutual dependence between leptin and orexin A and between leptin and ghrelin. These energy homeostasis indicators directly or indirectly influence the secretion of LH and GH and their endocrine activity is modulated by photoperiod in seasonal animals.

\section{Declaration of interest}

The authors have no conflicts of interest to declare.

\section{Acknowledgments}

The authors sincerely thank Prof. Arieh Gertler for providing the ovine leptin antagonist. We also acknowledge the assistance of Dr. Katarzyna Romanowicz.

\section{References}

Accorsi P.A., Munno A., Gamberoni M., Viggiani R., De Ambrogi M., Tamanin i C., S e r e n E. (2007). Role of leptin on growth hormone and prolactin secretion by bovine pituitary explants. J. Dairy Sci., 90: 1683-1691.

Amstalden M., Garcia M.R., Stanko R.L., Nizielski S.E., Morrison C.D., Keisle r D.H. (2002). Central infusion of recombinant ovine leptin normalizes plasma insulin and stimulates a novel hypersecretion of luteinizing hormone after short-term fasting in mature beef cows. Biol. Reprod., 66: 1555-1561.

A m stalden M., Zi eb a D.A., Edwards J.F., Harms P.G., We $1 \mathrm{sh}$ T.H. Jr., Stanko R.L. (2003). Leptin acts at the bovine adenohypophysis to enhance basal and gonadotropin-releasing hormone-mediated release of luteinizing hormone: differential effects are dependent upon nutritional history. Biol. Reprod., 69: 1539-1544.

Anukulkitch C., R a o A., P ereir a A., M c Ew an J., C l arke I.J. (2010). Expression of genes for appetite-regulating peptides in the hypothalamus of genetically selected lean and fat sheep. Neuroendocrinology, 91: 223-238.

A r che r Z.A., F in d l a y P.A., R h ind S.M., M e r c e r J.G., A d a m C.L. (2002). Orexin gene expression and regulation by photoperiod in the sheep hypothalamus. Regul. Pept., 104: 41-45.

B a c k hole r K., S mith J., C lark e I.J. (2009). Melanocortins may stimulate reproduction by activating orexin neurons in the dorsomedial hypothalamus and kisspeptin neurons in the preoptic area of the ewe. Endocrinology, 150: 5488-5497.

B a r b C.R., Matteri R.L. (2005). Orexin-B modulates luteinizing hormone and growth hormone secretion from porcine pituitary cells in culture. Domest. Anim. Endocrinol., 28: 331-337.

Barenton B., Ravault J., Chabanet C., Daveau A., Pelletier J., Ortavant R. (1988). Photoperiodic control of growth hormone secretion and body weight in rams. Domest. Anim. Endocrinol., 5: 247-255.

$\mathrm{C}$ h e $\mathrm{n} \mathrm{C.,} \mathrm{X} \mathrm{u} \mathrm{R.} \mathrm{(2003).} \mathrm{The} \mathrm{in} \mathrm{vitro} \mathrm{regulation} \mathrm{of} \mathrm{growth} \mathrm{hormone} \mathrm{secretion} \mathrm{by} \mathrm{orexins.} \mathrm{Endocrine,}$ 22: $57-66$ 
C l a r k e I.J. (2014). Interface between metabolic balance and reproduction in ruminants: focus on the hypothalamus and pituitary. Horm. Behav., 66: 15-40.

Cocchi D., De Gennaro Colonna V., Bagnasco M., Bonacci D., Müller E.E. (1999). Leptin regulates GH secretion in the rat by acting on GHRH and somatostatinergic functions. J. Endocrinol., 162: 95-99.

Dovolou E., Chadio S., Messinis I.E., Rekkas C.A., Deligiannis C., Kalogian$\mathrm{n}$ is D., A mirid is G.S. (2013). Human ghrelin decreases pituitary response to GnRH in superovulated ewes. Theriogenology, 80: 262-268.

Dvorak P., B e cka S., Krejci P., Chrpova M. (1978). Radioimmunoassay of bovine growth hormone. Radiochem. Radioanal. Lett., 34: 160-166.

Grouselle D., Chaillou E., Caraty A., Bluet-Pajot M.T., Zizzari P., Tillet Y., E p e 1 b a u m J. (2008). Pulsatile cerebrospinal fluid and plasma ghrelin in relation to growth hormone secretion and food intake in the sheep. J. Neuroendocrinol., 20: 1138-1146.

Harrison J.L., Miller D.W., Findlay P.A., A d a m C.L. (2008). Photoperiod influences the central effects of ghrelin on food intake, GH and LH secretion in sheep. Neuroendocrinology, 87: $182-192$.

Hashizume T., Horiuchi M., Nonaka S., Kas uy E., Kojima M., Hos oda H., Kang a w a K. (2005). Effects of ghrelin on growth hormone secretion in vivo in ruminants. Regul. Pept., 126: 61-65.

I q b a 1 J., M a n l e y T.R., C i o fi P., C l a r k e I.J. (2005). Reduction in adiposity affects the extent of afferent projections to growth hormone-releasing hormone and somatostatin neurons and the degree of colocalization of neuropeptides in growth hormone-releasing hormone and somatostatin cells of the ovine hypothalamus. Endocrinology, 146: 4776-4785.

I q b a 1 J., K u ro s e Y., C a n n y B., C l a r k e I.J. (2006). Effects of central infusion of ghrelin on food intake and plasma levels of growth hormone, luteinizing hormone, prolactin, and cortisol secretion in sheep. Endocrinology, 147: 510-519.

I qba 1 J., Pompolo S., Murakami T., Grouzmann E., Sakurai T., Me is ter B., C lar k e I.J. (2001). Immunohistochemical characterization of localization of long-form leptin receptor (OB-Rb) in neurochemically defined cells in the ovine hypothalamus. Brain Res., 920: 55-64.

Kirsz K., Szczesna M., Molik E., Misztal T., Wojtowicz A.K., Zieba D.A. (2012). Seasonal changes in the interactions among leptin, ghrelin, and orexin in sheep. J. Anim. Sci., 90: 2524-2531.

K ir s z K., S z c z e s n a M., D u de k K., B a r t l e w s k i P.M., Z i e b a D.A. (2014). Influence of season and nutritional status on the direct effects of leptin, orexin-A and ghrelin on luteinizing hormone and growth hormone secretion in the ovine pituitary explant model. Domest. Anim. Endocrinol., 48: 69-76.

Kohsaka A., Watanobe H., Kakizaki Y., Suda T., Schiöth H.B. (2001). A significant participation of orexin-A, a potent orexigenic peptide, in the preovulatory luteinizing hormone and prolactin surges in the rat. Brain Res., 898: 166-170.

Lebrethon M.C., Aganina A., Fournier M., Gérard A., Parent A.S., Bourguign o n J.P. (2007). Effects of in vivo and in vitro administration of ghrelin, leptin and neuropeptide mediators on pulsatile gonadotrophin-releasing hormone secretion from male rat hypothalamus before and after puberty. J. Neuroendocrinol., 19: 181-188.

López M., S e o ne L.M., Tovar S., Nogueiras R., Diéguez C., Señarís R. (2004). Orexin-A regulates growth hormone-releasing hormone mRNA content in a nucleus-specific manner and somatostatin mRNA content in a growth hormone-dependent fashion in the rat hypothalamus. Eur. J. Neurosci., 19: 2080-2088.

Luque R.M., Huang Z.H., Shah B., Mazzone T., K in e man R.D. (2007). Effects of leptin replacement on hypothalamic-pituitary growth hormone axis function and circulating ghrelin levels in ob/ob mice. Am. J. Physiol. - Endoc. M., 292: E891-E899.

Mill e r D., F ind l a y P.A., M o r r i s o n M.A., R a v e r N., A d a m C.L. (2002). Seasonal and dosedependent effects of intracerebroventricular leptin on LH secretion and appetite in sheep. J. Endocrinol., 175: 395-404.

Nagatani S., Zeng Y., Ke is ler D.H., Foster D.L., J a ffe C.A. (2000). Leptin regulates pulsatile luteinizing hormone and growth hormone secretion in the sheep. Endocrinology, 141: 3965-3975. 
Nonaka S., Hashizume T., Kasuya E. (2005). Effects of leptin on the release of luteinizing hormone, growth hormone and prolactin from cultured bovine anterior pituitary cells. Anim. Sci. J., 76: 435-440.

Polkowska J., Gajewska A., Wańkowska M., Misztal T., Wójcik-Gładysz A. (2012). The effect of intracerebroventricular infusions of ghrelin or short fasting on the gene expression and immunoreactivity of neuropeptide $\mathrm{Y}$ in the hypothalamic neurons in prepubertal female lambs: a morphofunctional study. J. Chem. Neuroanat., 46: 45-50.

P u S., J a in M.R., K a $1 \mathrm{r}$ a P.S., K a $1 \mathrm{r}$ a S.P. (1998). Orexins, a novel family of hypothalamic neuropeptides, modulate pituitary luteinizing hormone secretion in an ovarian steroid-dependent manner. Regul. Pept., 78: 133-136.

Ru s s e 1 A.J.F., D on e y J.M., Gunn R.G. (1969). Subjective assessment of body fat in live sheep. J. Agric. Sci., 72: 451-454.

R u s s e 11 S.H., S m a 11 C.J., K e n n e d y A.R., S t a n 1 e y S.A., S e th A., M u r ph y K.G., Tah e ri S., G hat e i M.A., B 1 o o m S.R. (2001). Orexin A interactions in the hypothalamo-pituitary gonadal axis. Endocrinology, 142: 5294-5302.

S art in J.L., D y e r C., M a t teri R., Buxton D., Bu on o mo F., Shores M., B a ker J., Os b or n e J.A., B ra d e n T., S t e e le B. (2001). Effect of intracerebroventricular orexin-B on food intake in sheep. J. Anim. Sci., 79: 1573-1577.

S e oane L., Tovar S., P erez D., Mallo F., Lopez M., S eñaris R., Cas a nueva F., D i e g u e z C. (2004). Orexin A suppresses in vivo GH secretion. Eur. J. Endocrinol., 150: 731-736.

S ir ot kin A.V., Gros s m a n R R. (2007). The role of ghrelin and some intracellular mechanisms in controlling the secretory activity of chicken ovarian cells. Comp. Biochem. Phys. A, 147: 239-246.

Sirotkin A.V., Chrenková M., Nitrayová S., Patraš P., Darlak K., Valenzuela F., Pinilla L., Tena-Sempere M. (2008). Effects of chronic food restriction and treatments with leptin or ghrelin on different reproductive parameters of male rats. Peptides, 29: $1362-1368$.

S mal1 C.J., Goubillon M.L., Murray J.F., Siddiqui A., Grimshaw S.E., Young H., Sivanesan V., Kal a matianos T., Kennedy A.R., Coen C.W., Bloom S.R., Wil s o n C.A. (2003). Central orexin A has site-specific effects on luteinizing hormone release in female rats. Endocrinology, 144: 3225-3236.

S p i c e r L.J., F r a n c is c o C.C. (1997). The adipose obese gene product, leptin: evidence of a direct inhibitory role in ovarian function. Endocrinology, 138: 3374-3379.

S tu p n i cki R., Mad ej A. (1976). Radioimmunoassay of LH in blood plasma of farm animals. Endokrinologie, 68: 6-13.

S un G., Ti a n Z., Ya o Y., Li H., Higu chi T. (2006). Central and/or peripheral immunoreactivity of orexin-A in pregnant rats and women. J. Mol. Endocrinol., 36: 131-138.

S zczesna M., K irs z K., K u charski M., Szy mas zek P., Z i eb a D.A. (2013). Obesity and leptin resistance: the role of growth hormone. Health, 5: 29-39.

Tamura T., Irahara M., Tezuka M., Ki yokawa M., A ono T. (1999). Orexins, orexigenic hypothalamic neuropeptides, suppress the pulsatile secretion of luteinizing hormone in ovariectomized female rats. Biochem. Biophys. Res. Commun., 264: 759-762.

Towhidi A., Khazali H., Zhandi M. (2007). Leptin is a metabolic signal for GnRH-LH/FSH Axis in feed-restricted ewes. Asian Australas. J. Anim. Sci., 20: 1039-1048.

Tra c z y k W., Prze k o p F. (1963). Methods of investigation of the function of the hypothalamus and hypophysis in chronic experiment in sheep. Acta Physiol. Pol., 14: 217-226.

Tritos N.A., Mastaitis J.W., Kokkotou E., Maratos-Flier E. (2001). Characterization of melanin concentrating hormone and preproorexin expression in the murine hypothalamus. Brain Res., 895: 160-166.

Wój c ik-Gładysz A., Wańkows ka M., Misztal T., Romanowicz K., P olkow ska J. (2009). Effect of intracerebroventricular infusion of leptin on the secretory activity of the GnRH/LH axis in fasted prepubertal lambs. Anim. Reprod. Sci., 114: 370-383.

Z a chow R.J., Mag offin D.A. (1997). Direct intraovarian effects of leptin: impairment of the synergistic action of insulin-like growth factor-I on follicle-stimulating hormone-dependent estradiol-17 beta production by rat ovarian granulosa cells. Endocrinology, 138: 847-850.

Zieba D., Amstalden M., Gallino J.L., Edwards J.F., Harms P.G., Williams G.L. 
(2003 a). Effects of leptin on basal and GHRH-stimulated GH secretion from the bovine adenohypophysis are dependent upon nutritional status. J. Endocrinol., 178: 83-89.

Z i e b a D.A., A m stald e n M., Ma c i el M.N., K e is le r D.H., R a ver N., Gert le r A., Wi l1 i a m s GL. (2003 b). Divergent effects of leptin on luteinizing hormone and insulin secretion are dose dependent. Exp. Biol. Med., 228: 325-330.

Z i e ba D.A., S zczesna M., K locek-Gorka B., Molik E., Misztal T., Willia m s G.L., R o m a now ic z K., S te pien E., Ke is ler D.H., Muraws ki M. (2008 a). Seasonal effects of central leptin infusion on secretion of melatonin and prolactin and on SOCS-3 gene expression in ewes. J. Endocrinol., 198: 147-155.

Zi eb a D.A., Szczesna M., K locek-Gorka B., Willia ms G.L. (2008 b). Leptin as a nutritional signal regulating appetite and reproductive processes in seasonally-breeding ruminants. J. Physiol. Pharmacol., 59 (Suppl. 9): 7-18.

Zi eba D.A., Kirsz K., Molik E., Romanowicz K., Wojtowicz A.K. (2011). Effects of orexigenic peptides and leptin on melatonin secretion during different photoperiods in seasonal breeding ewes: an in vitro study. Domest. Anim. Endocrinol., 40: 139-146.

Received: 22 II 2016

Accepted: 2 VI 2016 